\title{
Lower cardiorespiratory fitness contributes to increased insulin resistance and fasting glycaemia in middle-aged South Asian compared with European men living in the UK
}

\author{
N. Ghouri • D. Purves • A. McConnachie • J. Wilson • \\ J. M. R. Gill • N. Sattar
}

Received: 21 December 2012 / Accepted: 17 May 2013 / Published online: 29 June 2013

(C) The Author(s) 2013. This article is published with open access at Springerlink.com

\begin{abstract}
Aims/hypothesis This study aimed to determine the extent to which increased insulin resistance and fasting glycaemia in South Asian men, compared with white European men, living in the UK, was due to lower cardiorespiratory fitness (maximal oxygen uptake $\left[\dot{V} \mathrm{O}_{2 \max }\right]$ ) and physical activity. Methods One hundred South Asian and 100 age- and BMImatched European men without diagnosed diabetes, aged 40-70 years, had fasted blood taken for measurement of glucose concentration, HOMA-estimated insulin resistance $\left(\mathrm{HOMA}_{\mathrm{IR}}\right)$, plus other risk factors, and underwent assessment of physical activity (using accelerometry), $\dot{V} \mathrm{O}_{2 \max }$, body size and composition, and demographic and other lifestyle factors. For 13 South Asian and one European man, $\mathrm{HbA}_{1 \mathrm{c}}$ levels were $>6.5 \%$ ( $\left.>48 \mathrm{mmol} / \mathrm{mol}\right)$, indicating potential undiagnosed diabetes; these men were excluded from the analyses. Linear regression models were used to determine the extent to which body size and composition, fitness and physical activity variables explained differences
\end{abstract}

J. M. R. Gill and N. Sattar are joint senior authors for this work

Electronic supplementary material The online version of this article (doi:10.1007/s00125-013-2969-y) contains peer-reviewed but unedited supplementary material, which is available to authorised users.

N. Ghouri $(\bowtie) \cdot$ J. Wilson · J. M. R. Gill $(\bowtie) \cdot$ N. Sattar

BHF Glasgow Cardiovascular Research Centre,

Institute of Cardiovascular and Medical Sciences,

College of Medical, Veterinary and Life Sciences,

University of Glasgow, Glasgow G12 8TA, UK

e-mail: nazim.ghouri@glasgow.ac.uk

e-mail: jason.gill@glasgow.ac.uk

D. Purves $\cdot$ A. McConnachie

Robertson Centre for Biostatistics, Institute of Health

and Wellbeing, University of Glasgow, Glasgow, UK in $\mathrm{HOMA}_{\mathrm{IR}}$ and fasting glucose between South Asian and European men.

Results $\mathrm{HOMA}_{\mathrm{IR}}$ and fasting glucose were $67 \%(p<0.001)$ and 3\% $(p<0.018)$ higher, respectively, in South Asians than Europeans. Lower $\dot{V} \mathrm{O}_{2 \max }$, lower physical activity and greater total adiposity in South Asians individually explained 68\% (95\% CI 45\%, 91\%), 29\% (11\%, 46\%) and 52\% (30\%, 80\%), respectively, and together explained $83 \%(50 \%, 119 \%)$ (all $p<0.001$ ) of the ethnic difference in $\mathrm{HOMA}_{\mathrm{IR}}$. Lower $\dot{V} \mathrm{O}_{2 \max }$ and greater total adiposity, respectively, explained $61 \%(9 \%$, $111 \%$ ) and $39 \%(9 \%, 76 \%)$ (combined effect $63 \%[8 \%$, $115 \%$ ]; all $p<0.05$ ) of the ethnic difference in fasting glucose. Conclusions/interpretation Lower cardiorespiratory fitness is a key factor associated with the excess insulin resistance and fasting glycaemia in middle-aged South Asian, compared with European, men living in the UK.

Keywords Adiposity · Ethnicity · Fitness · Glycaemia · Insulin resistance $\cdot$ Maximal oxygen uptake $\cdot$ Obesity

Physical activity $\cdot$ Sedentary $\cdot$ South Asian

$\begin{array}{ll}\text { Abbreviations } \\ \text { ALT } & \text { Alanine aminotransferase } \\ \text { AST } & \text { Aspartate aminotransferase } \\ \text { CRP } & \text { C-reactive protein } \\ \text { CURVES } & \begin{array}{l}\text { Carotid Ultrasound and Risk of Vascular disease } \\ \text { in Europeans and South Asians study }\end{array} \\ \text { GGT } & \gamma \text {-Glutamyltransferase } \\ \text { HOMA } & \text { HOMA-estimated insulin resistance } \\ \text { MVPA } & \text { Moderate-to-vigorous physical activity } \\ \text { SES } & \text { Socioeconomic status } \\ \text { SIMD } & \text { Scottish Index of Multiple Deprivation } \\ \dot{V} \mathrm{O}_{2 \max } & \text { Maximal oxygen uptake }\end{array}$




\section{Introduction}

South Asians living in the UK have a three- to fivefold increased prevalence of type 2 diabetes and develop the disease around a decade earlier and at a lower BMI compared with white Europeans $[1,2]$. In addition, non-diabetic South Asians exhibit higher glucose levels than Europeans [3, 4]. While the mechanisms for their higher risk are not fully understood, greater insulin resistance is a strong candidate $[3,5,6]$.

Adiposity [7-9], cardiorespiratory fitness [8, 10] and physical activity $[11,12]$ are key factors influencing insulin resistance, glycaemia and diabetes risk. South Asians carry more body fat than Europeans and this may be distributed more centrally $[5,13,14]$. However, it appears that South Asians remain more insulin resistant than Europeans after matching or adjustment for a range of adiposity markers $[6$, 9]. Furthermore, limited data from small studies suggest that cardiorespiratory fitness, as assessed by maximal oxygen uptake $\left(\dot{V} \mathrm{O}_{2 \max }\right)$, is $10-20 \%$ lower in South Asians than in matched Europeans $[6,15,16]$, with our previous data [6] showing that adjustment for $\dot{V} \mathrm{O}_{2 \max }$ attenuated the difference in insulin sensitivity between young South Asian and European men. In addition, habitual levels of physical activity among South Asians living in the UK appear lower than in Europeans [17-20]. Low physical activity has been shown to explain part of the excess cardiovascular disease risk observed in South Asians [18], and could conceivably contribute to their increased diabetes risk. However, the data available on physical activity in South Asians have been obtained from self-reported questionnaires; these have limited validity compared with objective measures [21, 22], and this is potentially exacerbated in South Asians because of cultural interpretation of the terminology used in the questionnaires [17]. Misclassification arising from the use of questionnaires to assess physical activity can substantially underestimate the true relationship between activity and risk of vascular and metabolic disease [23, 24].

Thus, from the available data, the extent to which lower cardiorespiratory fitness and lower physical activity contributes to increased insulin resistance and glycaemia in South Asians is not established. We hypothesised that these factors would explain a substantial proportion of the increased insulin resistance and glycaemia observed in South Asian men living in the UK.

\section{Methods}

Participants and recruitment All participants (100 South Asians, 100 Europeans) were recruited to the Carotid Ultrasound and Risk of Vascular disease in Europeans and South Asians (CURVES) study, which had the primary aim of comparing prevalence of, and risk factors for, carotid atherosclerotic plaques between middle-aged South Asian and European men. South Asians (defined as having both parents of Indian, Pakistani, Bangladeshi or Sri Lankan origin) and European (both parents of white European origin) men, aged 40-70 years, without coronary heart disease (symptoms of angina, previously labelled ischaemic heart disease, previous myocardial infarction, coronary artery bypass graft, percutaneous transluminal coronary angioplasty), cerebrovascular disease, peripheral vascular disease or known diabetes were recruited to undertake a number of cardiometabolic investigations as described below. Individuals with musculoskeletal or other disorders (e.g. significant respiratory or circulatory disorder) that would prevent treadmill exercise testing were also excluded.

Volunteers were recruited via: (1) local advertising/wordof-mouth; and (2) by writing to potentially eligible participants identified from four local primary-care practice databases. The majority of participants (95 South Asians and 93 Europeans) were recruited by method (1). Using method (2), 470 potential volunteers (220 South Asians and 250 Europeans) meeting the study inclusion criteria were identified and sent letters inviting their participation. Fifteen individuals (seven South Asians, eight Europeans) replied positively. Three of these individuals did not respond to further attempts at contact: thus, 12 participants (five South Asians, seven Europeans) were recruited to the study by method (2). Participants were given feedback on their personal health data and received $£ 20$ to cover travel/transport costs, but no other participation incentive. All participants were resident and registered with a primary-care physician in Scotland. The study was approved by the West of Scotland Research Ethics Committee and conducted according to the principles expressed in the Declaration of Helsinki. All participants gave written informed consent.

Participants' health history, including smoking status and family health history, was determined by questionnaire. Years of education was determined by questionnaire. Socioeconomic status (SES) was determined using the Scottish Index of Multiple Deprivation (SIMD) 2006 score (www. scotland.gov.uk/Topics/Statistics/SIMD) and categorised in quintiles, with quintile 1 representing the most affluent and quintile 5 representing the most deprived group. Habitual diet was assessed using a 120 item food-frequency questionnaire [25].

Anthropometry Height, body mass, circumferences at five sites (waist, hip, mid-upper arm, mid-thigh and mid-calf) and skinfolds at seven sites (biceps, triceps, subscapular, suprailiac, supraspinale, thigh and calf) were measured by the same trained investigator (J. Wilson) using international standard protocols [26] in all participants. The between-day coefficient of variation for all skinfold measurements was 
$<5 \%$. Total body lean and fat masses were measured using air displacement plethysmography, with participants wearing only shorts or underwear (BOD POD body composition system, Life Measurement Instruments, CA, USA), as described previously [27].

Blood biochemistry and BP measurements Venous blood samples were obtained after an overnight fast of 10-12 h. Glucose, $\mathrm{HbA}_{1 \mathrm{c}}$, total cholesterol, HDL-cholesterol, LDLcholesterol, triacylglycerol, $\gamma$-glutamyltransferase (GGT), alanine aminotransferase (ALT), aspartate aminotransferase (AST) and C-reactive protein (CRP) were analysed on the day of collection in the National Health Service Biochemistry Laboratory in Glasgow, using standard automated enzymatic (for glucose, lipids and liver function tests), immunoturbidimetric (CRP) and HPLC $\left(\mathrm{HbA}_{1 \mathrm{c}}\right)$ methods. This laboratory participates in the UK National External Quality Assessment Service (UKNEQAS) scheme and all tests had interassay $\mathrm{CVs}<5 \%$. Plasma was stored at $-80^{\circ} \mathrm{C}$ for subsequent measurement of insulin, using a commercially available ELISA (Mercodia, Uppsala, Sweden), in a single batch at the end of the study. HOMA-estimated insulin resistance $\left(\mathrm{HOMA}_{\mathrm{IR}}\right)$ was calculated as previously described [28].

BP was measured after $\geq 15$ min of seated rest using an automated BP monitor (Omron HEM705CP, Omron Healthcare UK Limited, Milton Keynes, UK), which had been validated according to the European Society of Hypertension International Protocol [29]. The mean of four BP readings was used in analysis.

Determination of cardiorespiratory fitness All participants had a clinical assessment and resting ECG prior to undertaking the exercise test to ensure no contraindications to maximal exercise. $\dot{V} \mathrm{O}_{2 \max }$ was determined by a continuous incremental uphill walking protocol [30], with 1 min expired air samples taken continuously using Douglas bags and heart rate monitored by short-range telemetry. Achievement of $\dot{V} \mathrm{O}_{2 \max }$ was verified by volitional exhaustion and confirmed by the achievement of a minimum of two of the three following criteria: (1) respiratory exchange ratio (RER) $\geq 1.15$; (2) heart rate $\geq 90 \%$ of age-predicted maximum; and (3) an increase in $\dot{V} \mathrm{O}_{2}$ of $<2.1 \mathrm{ml} \mathrm{kg}^{-1} \mathrm{~min}^{-1}$ between the last two bags of collected expired air [30, 31].

Measurement of physical activity Participants wore accelerometers (GT3X+ or ActiTrainer; ActiGraph LLC, Pensacola, FL, USA) on the left or right hip at all times, except when showering, swimming and sleeping, for 7 consecutive days to objectively assess physical activity levels. Vertical axis accelerometer readings were summarised in $60 \mathrm{~s}$ epochs and Freedson cut-points were used to define intensity domains [32]. Data from participants with at least $10 \mathrm{~h}$ of daily accelerometer wear time for 4 days were included in the analysis. Non-wear was defined by intervals of $\geq 60 \mathrm{~min}$ of zero activity counts [33]. Wear time was calculated by subtracting non-wear time from $24 \mathrm{~h}$. Activity count values of $<100$ count $\min ^{-1}$ were defined as sedentary behaviour [34].

Data analysis The sample size for the CURVES study was based on the assumption that prevalence of carotid plaques (to be reported elsewhere) would be 50\% higher in South Asians than Europeans. Having 100 participants in each group would enable this difference to be detected with $80 \%$ power at $p<0.05$. Based on our previously published data [6], this number of participants would enable detection of differences of $\sim 0.4$ units, $\sim 3 \mathrm{ml} \mathrm{kg}^{-1} \min ^{-1}$ and $\sim 2 \mathrm{~kg}$ in $\mathrm{HOMA}_{\mathrm{IR}}, \dot{V} \mathrm{O}_{2 \max }$ and fat mass, respectively, with the same power, between the South Asian and European groups.

Summary statistics are presented for all variables for both South Asian and European men. Continuous variables were compared between the ethnic groups by $t$ tests (or Wilcoxon rank sum test for non-normally distributed variables) and Fisher's exact test for categorical variables.

Factor analysis was used to reduce the number of anthropometric variables into underlying latent factors [35]. Three factors emerged relating to 'total adiposity' (identified by biceps, triceps, subscapular, supraspinale, suprailiac, thigh and calf skinfolds, and fat mass), 'body size' (height, lean mass and hip, mid-thigh and mid-calf circumferences) and 'central adiposity' (waist circumference and waist-to-hip ratio). Factor loadings are shown in electronic supplementary material (ESM) Table 1. A summary measure was calculated to describe each factor. Each variable was standardised (by subtracting the mean and dividing by the SD), averaged according to the factor analysis groups and then standardised again. Initially, linear regression models, adjusted for ethnicity, were used to assess associations between total adiposity, body size, central adiposity, physical activity, sedentary behaviour and fitness (expressed as standardised measures) on HOMA $_{I R}$ and fasting glucose concentration. The effects of potential confounding covariates (age, education, SES, smoking, alcohol, diabetes family history) on $\mathrm{HOMA}_{\mathrm{IR}}$ and fasting glucose concentration were also assessed. Both outcome variables were log transformed (to base $e$ ) for analysis. The relative effects of ethnicity on $\mathrm{HOMA}_{\mathrm{IR}}$ and glucose were then calculated: when it was the only predictor in the model; after separate adjustment for total adiposity, body size, central adiposity, physical activity, sedentary behaviour and fitness; and in the final model, including adjustment for all of the above variables that significantly influenced the ethnicity effect. Thus, this analysis enabled determination of the extent to which differences in $\mathrm{HOMA}_{\mathrm{IR}}$ and fasting glucose concentration between South Asians and Europeans could be explained by body composition, fitness and 
Table 1 Demographic and metabolic variables for South Asian and European men
Values are mean (SD) for normally distributed variables with $p$ values calculated by $t$ tests, and median (interquartile range) for non-normally distributed variables with $p$ values calculated by Wilcoxon test; $p$ values for categorical variables were calculated by Fisher's exact test

${ }^{\text {a }} n=98$ for Europeans

${ }^{\mathrm{b}} n=86$ for South Asians

${ }^{\mathrm{c}}$ Wilcoxon test

\begin{tabular}{|c|c|c|c|}
\hline Variable & South Asian $(n=87)$ & European $(n=99)$ & $p$ value \\
\hline \multicolumn{4}{|c|}{ Demographic and lifestyle variables } \\
\hline Age (years) & $48.3(6.8)$ & $49.7(6.8)$ & 0.162 \\
\hline Body mass $(\mathrm{kg})$ & $82.0(12.1)$ & $85.7(13.9)$ & 0.056 \\
\hline Height (m) & $1.74(0.07)$ & $1.79(0.06)$ & $<0.001$ \\
\hline $\operatorname{BMI}\left(\mathrm{kg} / \mathrm{m}^{2}\right)$ & $27.1(3.8)$ & $26.9(4.3)$ & 0.700 \\
\hline Years in education & $15.4(3.4)$ & $14.4(3.2)$ & 0.042 \\
\hline SIMD quintile, $n(\%)$ & & & 0.751 \\
\hline 1 & $6(6.9)$ & $7(7.1)$ & \\
\hline 2 & $10(11.5)$ & $13(13.1)$ & \\
\hline 3 & $16(18.4)$ & $19(19.2)$ & \\
\hline 4 & $23(26.4)$ & $18(18.2)$ & \\
\hline 5 & $32(36.8)$ & $42(42.4)$ & \\
\hline Smoking status, $n(\%)$ & & & $<0.001$ \\
\hline Never smoker & $71(81.6)$ & $54(54.5)$ & \\
\hline Ex-smoker & $5(5.7)$ & $35(35.4)$ & \\
\hline Current & $11(12.6)$ & $10(10.1)$ & \\
\hline Alcohol consumption ${ }^{\mathrm{a}}, n(\%$ & & & $<0.001$ \\
\hline None & $81(93.1)$ & $10(10.2)$ & \\
\hline$\leq 20$ units per week & $4(4.6)$ & $69(70.4)$ & \\
\hline$\geq 21$ units per week & $2(2.3)$ & $19(19.4)$ & \\
\hline \multicolumn{4}{|c|}{ Parental diabetes status ${ }^{\mathrm{a}}, n(\%)$} \\
\hline Yes & $50(57.5 \%)$ & $12(12.2 \%)$ & $<0.001$ \\
\hline \multicolumn{4}{|l|}{ Sibling diabetes status ${ }^{\mathrm{a}}, n(\%)$} \\
\hline Yes & $13(14.9 \%)$ & $2(2.0 \%)$ & 0.002 \\
\hline \multicolumn{4}{|l|}{ Metabolic variables } \\
\hline Glucose $(\mathrm{mmol} / \mathrm{l})$ & $5.3(4.9,5.7)$ & $5.1(4.8,5.4)$ & 0.018 \\
\hline $\mathrm{HbA}_{1 \mathrm{c}}(\mathrm{mmol} / \mathrm{mol})^{\mathrm{b}}$ & $39.0(37.0,41.0)$ & $36.0(33.0,38.0)$ & $<0.001$ \\
\hline $\mathrm{HbA}_{1 \mathrm{c}}(\%)^{\mathrm{b}}$ & $5.7(5.5,5.9)$ & $5.4(5.2,5.6)$ & $<0.001$ \\
\hline Insulin $(\mathrm{pmol} / 1)^{\mathrm{b}}$ & $88.9(69.5,119.5)$ & $54.2(36.8,79.9)$ & $<0.001$ \\
\hline $\mathrm{HOMA}_{\mathrm{IR}}^{\mathrm{b}}$ & $3.0(2.4,4.2)$ & $1.8(1.1,2.6)$ & $<0.001$ \\
\hline Total cholesterol $(\mathrm{mmol} / \mathrm{l})$ & $5.4(1.0)$ & $5.6(1.0)$ & 0.107 \\
\hline HDL-cholesterol (mmol/l) & $1.1(1.0,1.3)$ & $1.3(1.1,1.6)$ & $<0.001$ \\
\hline LDL-cholesterol $(\mathrm{mmol} / \mathrm{l})$ & $3.5(0.9)$ & $3.6(0.8)$ & 0.458 \\
\hline Triacylglycerol (mmol/l) & $1.4(1.0,2.2)$ & $1.3(0.9,1.8)$ & 0.135 \\
\hline AST $(\mu \mathrm{kat} / \mathrm{l})$ & $0.39(0.11)$ & $0.42(0.14)$ & 0.100 \\
\hline $\operatorname{ALT}(\mu \mathrm{kat} / \mathrm{l})$ & $0.43(0.35,0.59)$ & $0.43(0.33,0.59)$ & 0.857 \\
\hline GGT $(\mu \mathrm{kat} / \mathrm{l})$ & $0.50(0.37,0.71)$ & $0.47(0.34,0.73)$ & 0.572 \\
\hline $\operatorname{CRP}(\mathrm{nmol} / \mathrm{l})^{\mathrm{a}}$ & $17.1(10.5,38.1)$ & $10.5(5.7,23.8)$ & 0.003 \\
\hline Systolic BP (mmHg) & $126.3(15.4)$ & $127.5(12.9)$ & 0.568 \\
\hline Diastolic BP (mmHg) & $77.8(9.1)$ & $74.9(7.2)$ & 0.018 \\
\hline
\end{tabular}

physical activity variables. The absolute differences in geometric means for $\mathrm{HOMA}_{\mathrm{IR}}$ and fasting glucose concentration between the groups were calculated for each model, using the mean value for continuous predictors and the reference level for any categorical variables; $95 \%$ CIs for the differences were derived by bootstrapping. The percentage change in the relative percentile difference between South Asians and Europeans in $\mathrm{HOMA}_{\mathrm{IR}}$ and fasting glucose concentration were calculated with $95 \%$ CIs and $p$ values derived by bootstrapping (reductions greater than $100 \%$ describe a change in direction of the effect).

The statistical software package $\mathrm{R}$ for Windows v2.14 (http://cran.r-project.org/) was used for all analysis. Statistical significance was accepted at $p<0.05$. 


\section{Results}

Demographic and metabolic variables Thirteen South Asian men and one European man who completed the study were subsequently noted to have $\mathrm{HbA}_{1 \mathrm{c}}$ concentrations $>6.5 \%$ (>48 $\mathrm{mmol} / \mathrm{mol})$ and/or fasting glucose concentrations $>7 \mathrm{mmol} / \mathrm{l}$, indicating possible undiagnosed diabetes. Their data were excluded from the analyses. Our final data set therefore included 87 South Asian and 99 European men. Demographic and metabolic variables for the final South Asian and European cohorts are presented in Table 1. There were no differences between groups in age or BMI, but the South Asians were shorter than the Europeans. South Asians also had completed more years in education, were less likely to smoke or consume alcohol and were more likely to have a parent or sibling with type 2 diabetes. There were no differences in SES. South Asians had significantly higher glucose, $\mathrm{HbA}_{1 \mathrm{c}}$, insulin, $\mathrm{HOMA}_{\mathrm{IR}}, \mathrm{CRP}$ and diastolic blood pressure, and lower HDL-cholesterol than the Europeans.

Body composition, fitness and physical activity variables Body composition, fitness and physical activity variables are presented in Table 2. There were no differences in waist or hip circumferences between the South Asian and European groups, but waist-to-hip ratio was higher in the South Asians. South Asians also had a smaller mid-thigh circumference, and higher values for all skinfold thicknesses than the Europeans. Lean mass was lower and fat mass and percentage body fat were higher in the South Asians. Total adiposity and central adiposity factors were higher and the body size factor
Table 2 Body composition, fitness, and physical activity variables for South Asian and European men
Values are mean (SD) for normally distributed variables with $p$ values calculated by $t$ tests, and median (interquartile range) for non-normally distributed variables with $p$ values calculated by Wilcoxon test

${ }^{\mathrm{a}} n=98$ for Europeans; ${ }^{\mathrm{b}} n=82$ for South Asians; ${ }^{\mathrm{c}} n=95$ for Europeans; ${ }^{\mathrm{d}} n=84$ for South Asians; ${ }^{\mathrm{e}} n=86$ for South Asians

${ }^{\mathrm{f}}$ Derived from biceps, triceps, subscapular, supraspinale, suprailiac, thigh, and calf skinfolds and fat mass

${ }^{g}$ Derived from height, lean mass and hip, mid-thigh and mid-calf circumferences

${ }^{\mathrm{h}}$ Derived from waist circumference and waist-to-hip ratio

${ }^{\mathrm{i}} n=97$ for Europeans; ${ }^{\mathrm{j}} n=83$ for Europeans and $n=75$ for South Asians

${ }^{\mathrm{k}}$ Wilcoxon test

\begin{tabular}{|c|c|c|c|}
\hline Variable & South Asian $(n=87)$ & European $(n=99)$ & $p$ value \\
\hline \multicolumn{4}{|l|}{ Anthropometric } \\
\hline \multicolumn{4}{|l|}{ Body circumference } \\
\hline Waist (cm) & $97.3(10.9)$ & $95.6(11.2)$ & 0.315 \\
\hline Hips $(\mathrm{cm})$ & $99.5(6.6)$ & $100.5(7.1)$ & 0.336 \\
\hline Waist-to-hip ratio & $0.98(0.07)$ & $0.95(0.06)$ & 0.009 \\
\hline Mid-upper arm (cm) & $34.5(8.2)$ & $33.4(3.3)$ & 0.238 \\
\hline Mid-thigh (cm) & $52.6(4.3)$ & $54.0(4.0)$ & 0.030 \\
\hline Mid-calf $(\mathrm{cm})$ & $37.7(3.4)$ & $38.6(4.1)$ & 0.101 \\
\hline \multicolumn{4}{|l|}{ Skinfold thickness } \\
\hline Biceps $(\mathrm{mm})^{\mathrm{a}}$ & $8.0(3.6)$ & $6.8(2.9)$ & 0.015 \\
\hline Triceps $(\mathrm{mm})$ & $16.4(5.8)$ & $12.6(4.3)$ & $<0.001$ \\
\hline Subscapular (mm) $)^{\mathrm{a}, \mathrm{b}}$ & $25.7(7.3)$ & $18.3(7.1)$ & $<0.001$ \\
\hline Suprailiac $(\mathrm{mm})^{\mathrm{c}, \mathrm{d}}$ & $23.4(6.2)$ & $18.2(6.2)$ & $<0.001$ \\
\hline Supraspinale (mm) & $18.0(6.6)$ & $12.6(5.4)$ & $<0.001$ \\
\hline Thigh $(\mathrm{mm})^{\mathrm{a}}$ & $19.1(7.9)$ & $14.6(5.7)$ & $<0.001$ \\
\hline Calf $(\mathrm{mm})^{\mathrm{e}}$ & $13.0(5.4)$ & $10.4(4.2)$ & $<0.001$ \\
\hline \multicolumn{4}{|l|}{ Fat and lean mass } \\
\hline Lean mass $(\mathrm{kg})^{\mathrm{a}}$ & $57.2(6.4)$ & $63.3(7.1)$ & $<0.001$ \\
\hline Fat mass $(\mathrm{kg})^{\mathrm{a}}$ & $24.4(9.0)$ & $21.8(9.7)$ & 0.058 \\
\hline Percentage body fat ${ }^{a}$ & $29.2(7.4)$ & $24.8(7.4)$ & $<0.001$ \\
\hline \multicolumn{4}{|l|}{ Summary anthropometric factors } \\
\hline Total adiposity ${ }^{\mathrm{f}}$ (standardised units) & $0.4(1.0)$ & $-0.3(0.9)$ & $<0.001$ \\
\hline Body size ${ }^{\mathrm{g}}$ (standardised units) & $-0.3(0.9)$ & $0.3(1.0)$ & $<0.001$ \\
\hline Central adiposity ${ }^{\mathrm{h}}$ (standardised units) & $0.1(1.0)$ & $-0.1(1.0)$ & 0.058 \\
\hline \multicolumn{4}{|l|}{ Fitness variables } \\
\hline$\dot{V} \mathrm{O}_{2 \max }(\mathrm{l} / \mathrm{min})^{\mathrm{a}}$ & $2.6(0.4)$ & $3.4(0.6)$ & $<0.001$ \\
\hline$\dot{V} \mathrm{O}_{2 \max }\left(\mathrm{ml} \mathrm{kg}^{-1} \min ^{-1}\right)^{\mathrm{a}}$ & $31.5(5.8)$ & $39.6(7.5)$ & $<0.001$ \\
\hline$\dot{V} \mathrm{O}_{2 \max }\left(\mathrm{ml} /[\mathrm{kg} \text { lean mass }]^{-1} \min ^{-1}\right)^{\mathrm{i}}$ & $44.7(6.4)$ & $53.0(7.8)$ & $<0.001$ \\
\hline \multicolumn{4}{|l|}{ Physical activity variables } \\
\hline Sedentary $(\% \text { of wear time })^{j}$ & $66.5(9.5)$ & $64.2(9.1)$ & 0.136 \\
\hline Light physical activity ( $\%$ of wear time $)^{\mathrm{j}}$ & $30.4(9.2)$ & $30.8(8.1)$ & 0.789 \\
\hline MVPA ( $\%$ of wear time $)^{\mathrm{j}}$ & $2.8(1.7,4.1)$ & $4.1(3.0,6.8)$ & $<0.001^{\mathrm{k}}$ \\
\hline Total accelerometer wear time $(\min / \text { day })^{\mathrm{j}}$ & $824.5(85.1)$ & $863.0(74.2)$ & 0.003 \\
\hline
\end{tabular}




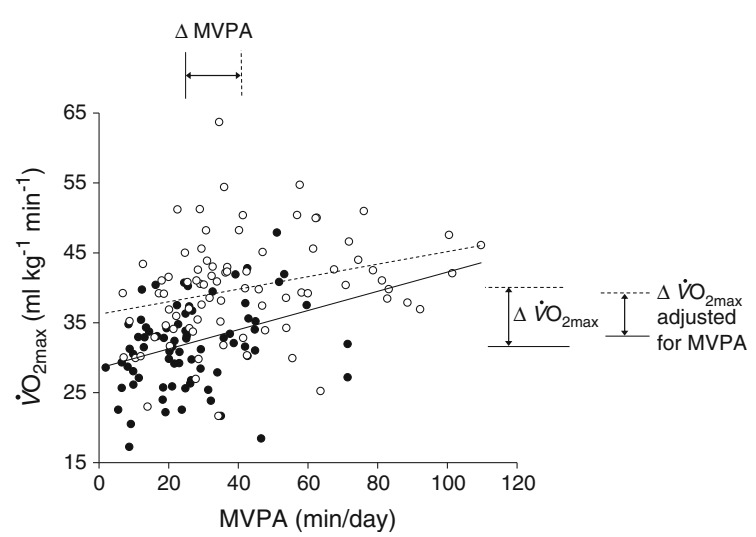

Fig. 1 Relationship between maximal oxygen uptake $\left(\dot{V} \mathrm{O}_{2 \max }\right)$ and MVPA in South Asian (black circles, solid line) and European (white circles, dotted line) men. Solid and dotted vertical bars indicate mean MVPA levels in South Asian and European men, respectively; the horizontal arrow shows the mean difference in MVPA between ethnic groups. Solid and dotted horizontal bars, with corresponding vertical arrows, indicate mean $V \mathrm{O}_{2 \max }$ values in South Asian and European men, respectively, and the mean ethnic difference, both unadjusted and adjusted for MVPA

was lower in South Asians than Europeans. Cardiorespiratory fitness (as assessed by $\dot{V} \mathrm{O}_{2 \max }$ ) was lower in South Asians than Europeans, irrespective of whether this was expressed in absolute terms (i.e. $1 / \mathrm{min}$ ) (lower on average by $24 \%$ ), per $\mathrm{kg}$ body mass (by $21 \%$ ) or per $\mathrm{kg}$ lean mass (by $16 \%$ ).

South Asians also engaged in less moderate-to-vigorous physical activity (MVPA) than Europeans: the proportion of time spent in MVPA was, on average, $~ 32 \%$ lower in South Asians than Europeans. This equated to South Asians engaging in $23 \mathrm{~min}$ MVPA/day compared with $\sim 34 \mathrm{~min} /$ day for the Europeans. There were significant correlations between $\dot{V} \mathrm{O}_{2 \max }$ (in $\mathrm{ml} \mathrm{kg}^{-1} \mathrm{~min}^{-1}$ ) and log MVPA in both South Asians $(r=0.326, p=0.004)$ and Europeans $(r=0.326$, $p=0.003$ ). However, the lower $\dot{V} \mathrm{O}_{2 \max }$ values in South Asians could not be explained by their lower levels of physical activity: South Asians' $\dot{V} \mathrm{O}_{2 \max }$ values were lower than those of Europeans across the range of MVPA levels, and their $\dot{V} \mathrm{O}_{2 \max }$ values remained significantly lower than Europeans after adjustment for MVPA (Fig. 1). Reported energy intake (expressed per $\mathrm{kg}$ body mass) did not differ between the Europeans and South Asians ( $83.2 \pm 25.1$ vs $\left.78.2 \pm 27.2 \mathrm{~kJ} \mathrm{~kg}^{-1} \mathrm{day}^{-1}, p=0.21\right)$. There were also no differences in reported protein, carbohydrate or fat intakes between the two groups (data not shown), but reported alcohol intake was higher in the Europeans than the South Asians ( $22.1 \pm 18.3$ vs $1.2 \pm 6.0 \mathrm{~g} /$ day, $p<0.001)$.

Associations between anthropometric, physical activity and fitness variables with $H O M A_{I R}$ and fasting glucose concentration Table 3 shows ethnicity-adjusted relative effects of anthropometric, physical activity and fitness variables on $\mathrm{HOMA}_{\mathrm{IR}}$ and fasting glucose concentration. $\mathrm{HOMA}_{\mathrm{IR}}$ increased with increasing total adiposity, body size, central adiposity and sedentary time and decreased with increasing MVPA and $\dot{V} \mathrm{O}_{2 \max }$. Fasting glucose concentration increased with increasing total adiposity and decreased with increasing $\dot{V} \mathrm{O}_{2 \max }$. For these analyses, $\dot{V} \mathrm{O}_{2 \max }$ was expressed in $\mathrm{ml} \mathrm{kg}^{-1} \mathrm{~min}^{-1}$, but results were similar when $\dot{V} \mathrm{O}_{2 \max }$ was expressed in $1 / \mathrm{min}$ or in $\mathrm{ml} \mathrm{kg}$ lean mass ${ }^{-1} \mathrm{~min}^{-1}$. The effects of potential confounding covariates on $\mathrm{HOMA}_{\mathrm{IR}}$ and fasting

Table 3 Associations (as relative effects) between $\mathrm{HOMA}_{\mathrm{IR}}$ and fasting glucose concentration with standardised anthropometric, physical activity and fitness variables

\begin{tabular}{|c|c|c|c|c|}
\hline \multirow[t]{2}{*}{ Predictor } & \multicolumn{2}{|l|}{$\mathrm{HOMA}_{\mathrm{IR}}$} & \multicolumn{2}{|c|}{ Fasting glucose concentration } \\
\hline & $\begin{array}{l}\text { Relative effect estimate } \\
(95 \% \mathrm{CI})\end{array}$ & $p$ value & $\begin{array}{l}\text { Relative effect estimate } \\
(95 \% \mathrm{CI})\end{array}$ & $p$ value \\
\hline \multicolumn{5}{|l|}{ Anthropometric variables } \\
\hline Total adiposity ${ }^{\mathrm{a}}$ & $1.40(1.30,1.50)$ & $<0.001$ & $1.02(1.00,1.03)$ & 0.013 \\
\hline Body size ${ }^{\mathrm{b}}$ & $1.21(1.12,1.31)$ & $<0.001$ & $1.00(0.99,1.02)$ & 0.666 \\
\hline Central adiposity ${ }^{\mathrm{c}}$ & $1.40(1.31,1.49)$ & $<0.001$ & $1.01(1.00,1.03)$ & 0.075 \\
\hline \multicolumn{5}{|l|}{ Physical activity variables } \\
\hline MVPA & $0.86(0.79,0.94)$ & 0.001 & $0.99(0.97,1.01)$ & 0.263 \\
\hline Sedentary & $1.10(1.01,1.20)$ & 0.024 & $1.01(0.99,1.02)$ & 0.299 \\
\hline \multicolumn{5}{|l|}{ Fitness variables } \\
\hline$\dot{V} \mathrm{O}_{2 \max }\left(\mathrm{ml} \mathrm{kg}^{-1} \min ^{-1}\right)$ & $0.74(0.68,0.80)$ & $<0.001$ & $0.98(0.97,1.00)$ & 0.020 \\
\hline
\end{tabular}

Relative effects (ratios of geometric means) are for a $1 \mathrm{SD}$ change in the predictor variable, adjusted for ethnicity

Values are presented with $95 \% \mathrm{CI}$ and $p$ values

${ }^{a}$ Derived from biceps, triceps, subscapular, supraspinale, suprailiac, thigh and calf skinfolds, and fat mass

${ }^{\mathrm{b}}$ Derived from height, lean mass and hip, mid-thigh and mid-calf circumferences

${ }^{\mathrm{c}}$ Derived from waist circumference and waist-to-hip ratio 


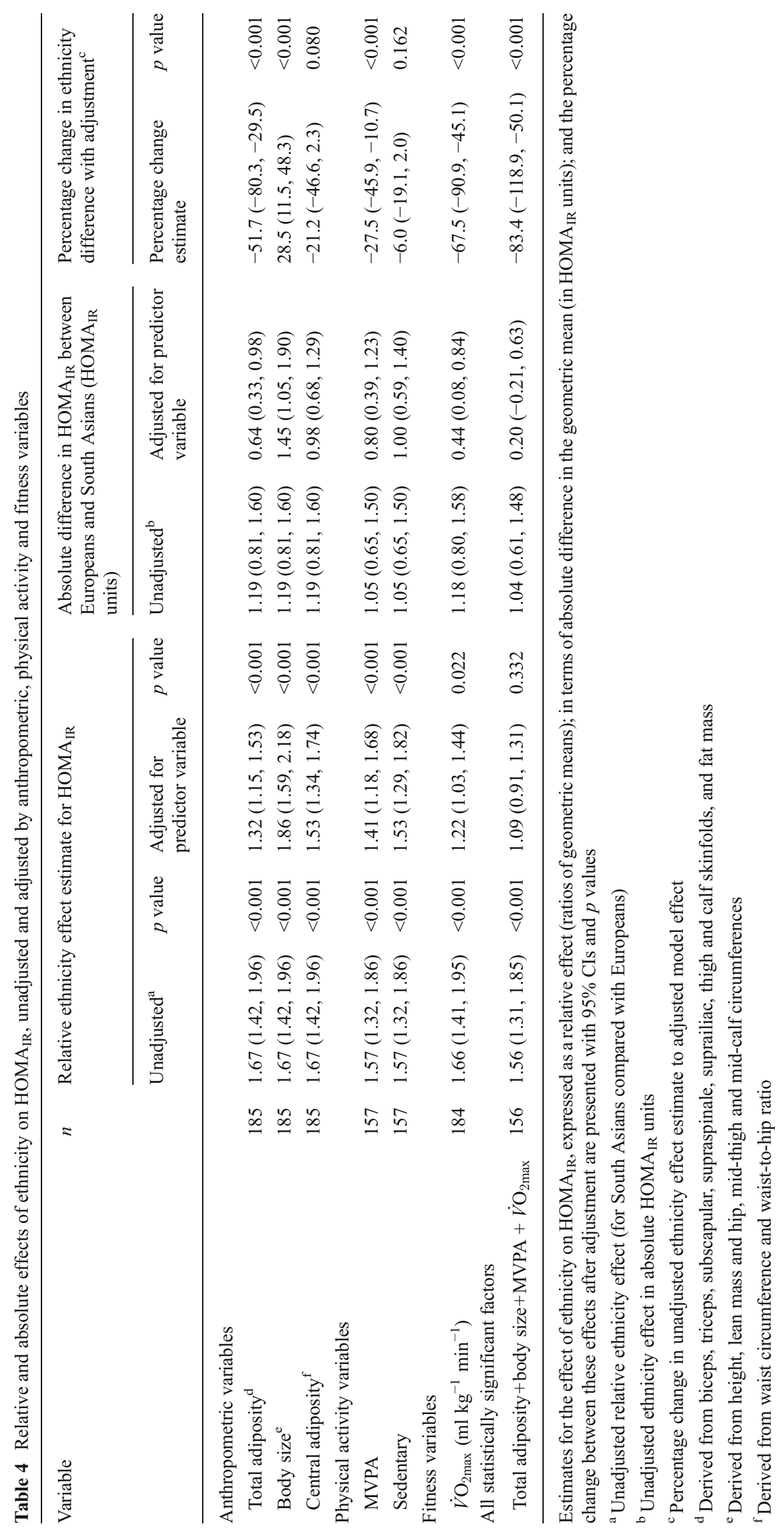


glucose concentration are shown in ESM Table 2. HOMA ${ }_{\text {IR }}$ was higher in ex-smokers (but not current smokers) than nonsmokers (by 26\% [95\% CI 2\%,56\%; $p=0.03]$ ). Other than this, none of the measured covariates was significantly associated with $\mathrm{HOMA}_{\mathrm{IR}}$ or fasting glucose concentration.

Contribution of anthropometric, physical activity and fitness variables to the difference in HOMA $A_{I R}$ between Europeans and South Asians Table 4 shows the effect of ethnicity, in relative and absolute terms, on $\mathrm{HOMA}_{\mathrm{IR}}$, unadjusted and in models adjusted for anthropometric, physical activity and fitness variables. In the unadjusted analysis, $\mathrm{HOMA}_{\mathrm{IR}}$ values in South Asians were 67\% (95\% CI 42\%, 96\%, $p<0.001)$ higher than the values observed in Europeans. Ethnicity contributed $18 \%$ of the total variance in $\mathrm{HOMA}_{\mathrm{IR}}$. Adjusting for total adiposity attenuated the difference in $\mathrm{HOMA}_{\mathrm{IR}}$ between ethnic groups by $51.7 \%(29.5 \%, 80.3 \%)$, whereas adjusting for body size increased the difference by $28.5 \%$ $(11.5 \%, 48.3 \%)$. Adjusting for MVPA reduced the difference in $\mathrm{HOMA}_{\mathrm{IR}}$ between South Asians and Europeans by $27.5 \%$ $(10.7 \%, 45.9 \%)$. However, the difference in $\dot{V} \mathrm{O}_{2 \max }$ between South Asians and Europeans explained more of the difference in $\mathrm{HOMA}_{\mathrm{IR}}$ than any other variable: adjustment for $\dot{V} \mathrm{O}_{2 \max }$ attenuated the difference in $\mathrm{HOMA}_{\mathrm{IR}}$ between ethnic groups by $67.5 \%(45.1 \%, 90.9 \%)$. This is further illustrated in Fig. 2. Adjustment for central adiposity or sedentary time did not significantly alter the ethnicity effect on HOMA $\mathrm{IR}$. Simultaneously adjusting for the four variables that significantly changed the ethnicity effect (total adiposity, body size, MVPA and $\dot{V} \mathrm{O}_{2 \max }$ ) attenuated the difference in $\mathrm{HOMA}_{\mathrm{IR}}$ between South Asians and Europeans by 83.4\% (50.1\%, $118.9 \%$ ). Repeating the analyses after adjustment for

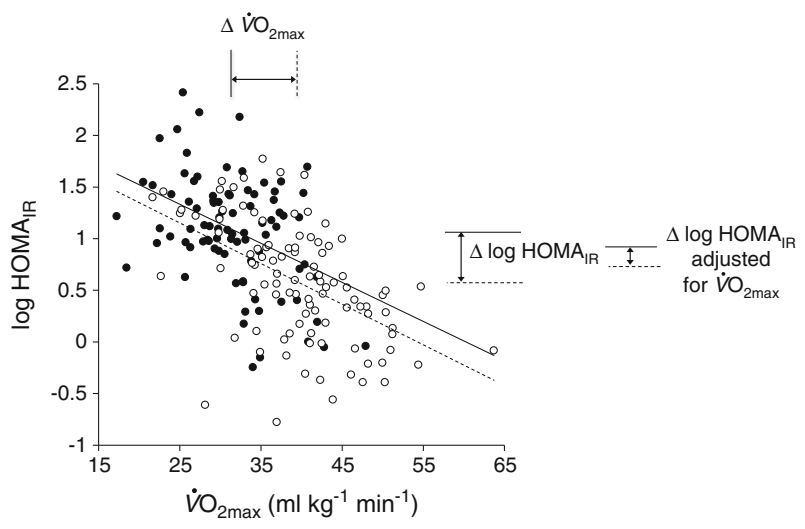

Fig. 2 Relationship between $\mathrm{HOMA}_{\mathrm{IR}}$ and $\dot{V} \mathrm{O}_{2 \max }$ in South Asian (black circles, solid line) and European (white circles, dotted line) men. $\mathrm{HOMA}_{\mathrm{IR}}$ values are displayed as natural logarithms. Solid and dotted vertical bars indicate mean $\dot{V} \mathrm{O}_{2 \max }$ values in South Asian and European men, respectively; the horizontal arrow shows the mean difference in $\dot{V} \mathrm{O}_{2 \max }$ between ethnic groups. Solid and dotted horizontal bars, with corresponding vertical arrows, indicate mean $\mathrm{HOMA}_{\mathrm{IR}}$ values in South Asian and European men and the mean ethnic difference, both unadjusted and adjusted for $\dot{V} \mathrm{O}_{2 \max }$ smoking, alcohol consumption, education and SES produced similar findings (ESM Table 3). In these confounder-adjusted analyses, the difference in $\dot{V} \mathrm{O}_{2 \max }$ between South Asians and Europeans explained $77.8 \%(38.4 \%, 132.2 \%)$ of the ethnic difference in $\mathrm{HOMA}_{\mathrm{IR}}$, and the contribution of total adiposity to the difference in $\mathrm{HOMA}_{\mathrm{IR}}$ between the ethnic groups was attenuated slightly to $41.3 \%(0.5 \%, 95.7 \%)$.

Contribution of anthropometric, physical activity and fitness variables to the difference in fasting glucose concentration between Europeans and South Asians Table 5 presents similar data for the fasting glucose concentration. In the unadjusted analysis, fasting glucose concentrations in South Asians were 3\% (95\% CI 1\%,6\%; $p=0.017)$ higher than in Europeans. Ethnicity contributed $3 \%$ of the variance in fasting glucose. Adjusting for total adiposity attenuated the ethnic difference in fasting glucose by $39.1 \%(9.4 \%, 76.1 \%)$. Similar to effects on $\mathrm{HOMA}_{\mathrm{IR}}, \dot{V} \mathrm{O}_{2 \max }$ explained more of the difference in fasting glucose concentration between South Asians and Europeans than any other variable, with adjustment for $\dot{V} \mathrm{O}_{2 \max }$ attenuating the ethnic difference by $60.7 \%$ $(9.2 \%, 111.0 \%)$. The ethnicity effect for fasting glucose concentration was not significantly influenced by body size, central adiposity, MVPA or sedentary time. Simultaneously adjusting for total adiposity and $\dot{V} \mathrm{O}_{2 \max }$ attenuated the ethnic difference in fasting glucose by $63.4 \%(8.2 \%, 114.6 \%)$. Repeating the analyses after adjustment for smoking, alcohol consumption, education and SES produced essentially similar findings (ESM Table 4), with $\dot{V} \mathrm{O}_{2 \max }$ still explaining more of the difference in fasting glucose concentration between the ethnic groups than other any variable $(-41.6 \%[-232.0 \%$, $-1.7 \%]$ ). In these confounder-adjusted analyses no other variables significantly contributed to the ethnicity difference.

\section{Discussion}

The main novel finding of this study was that low cardiovascular fitness, as measured by the gold-standard maximal incremental treadmill test, was the single most important factor associated with the increased insulin resistance and fasting glycaemia observed in middle-aged South Asian compared with European men living in the UK. Ethnicity explained $18 \%$ of the variance in $\mathrm{HOMA}_{\mathrm{IR}}$, with $\mathrm{HOMA}_{\mathrm{IR}}$ values being $67 \%$ higher in South Asians than Europeans. South Asians' lower $\dot{V} \mathrm{O}_{2 \max }$ levels (statistically) explained more than two-thirds of this ethnic difference. The ethnic difference in fasting glucose concentration was less pronounced. Ethnicity explained 3\% of the variance in fasting glucose, and values were 3\% higher in South Asians than Europeans: nevertheless over $60 \%$ of the ethnic difference in 


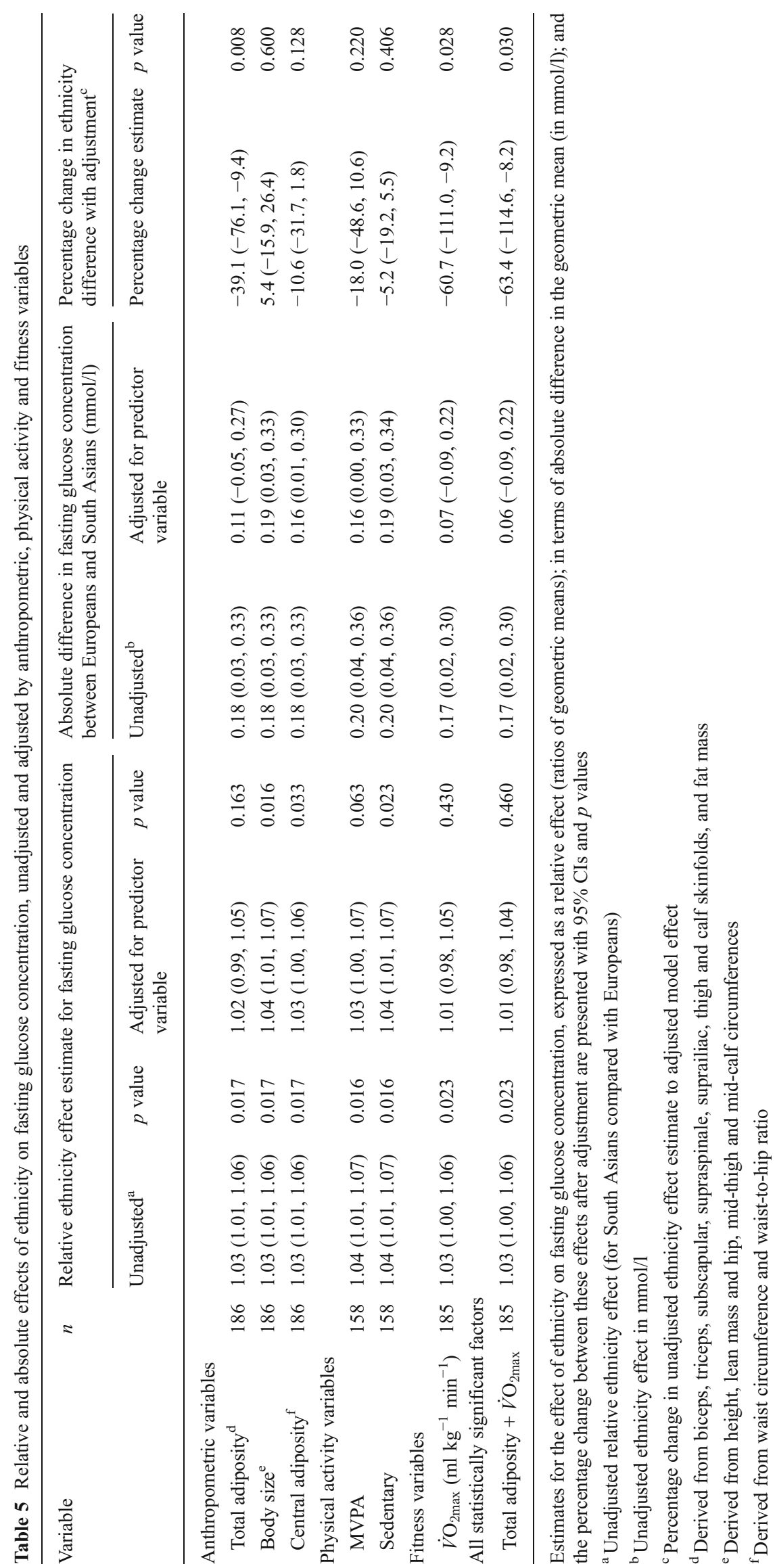


fasting glucose $(\sim 0.1 \mathrm{mmol} / 1)$ could be explained by $\dot{V} \mathrm{O}_{2 \max }$. Higher total adiposity and lower MVPA in South Asians were also associated with their greater $\mathrm{HOMA}_{\mathrm{IR}}$; their increased total adiposity was also associated with their higher fasting glucose values. Fitness, anthropometric and physical activity variables together explained over four-fifths of the increased insulin resistance and three-fifths of the increased glycaemia observed in South Asians.

The finding that greater total adiposity explained about half South Asians' increased insulin resistance and two-fifths of their increased fasting glycaemia compared with Europeans is consistent with other reports [5, 13, 14], although interestingly South Asians' smaller body size acted in the opposite direction, appearing to attenuate the difference in HOMA $_{I R}$ between the groups. Furthermore, our findings demonstrate, using robust objective measures, that levels of physical activity were significantly lower in South Asians than Europeans in our sample, which is consistent with the suggestions from previous self-reported data [17-20], and reveals for the first time that this contributes to their greater insulin resistance. However, the most striking finding from this study is the extent to which lower cardiorespiratory fitness was associated with South Asians' insulin-resistant phenotype. This is consistent with data from animal models that have demonstrated a causal link between low fitness and insulin resistance [36] and with epidemiological data reporting a 2.6-fold increased risk of incident type 2 diabetes, independent of BMI, in men with low cardiorespiratory fitness levels compared with high levels [10]. Importantly, the present data demonstrate that although fitness increases with increasing physical activity, South Asians' lower $\dot{V} \mathrm{O}_{2 \max }$ values could not be explained simply by their lower physical activity levels. South Asians had lower fitness levels than Europeans at all levels of physical activity, and adjusting for MVPA only modestly attenuated the ethnic difference in $\dot{V} \mathrm{O}_{2 \max }$ (see Fig. 1). Interestingly, recent data from the National Health and Nutrition Examination Survey (NHANES) support the suggestion of innate differences in fitness between ethnic groups, with Ceaser and colleagues reporting systematic differences in $\dot{V} \mathrm{O}_{2 \max }$ between Mexican Americans (highest), non-Hispanic whites and non-Hispanic blacks (lowest) that were independent of time spent in (self-reported) physical activity and demographic factors [37]. There is a strong heritable component to $\dot{V} \mathrm{O}_{2 \max }$, with heritability estimates in this trait of up to $50 \%[38,39]$; thus, it seems likely that there will be a genetic (and/or early origins) contribution to the lower $\dot{V} \mathrm{O}_{2 \max }$ values in South Asians. We have recently reported that South Asians have a reduced ability to oxidise fat during exercise compared with Europeans [6], suggesting that there may be innate differences in the physiology of South Asians compared with Europeans that may contribute to this effect. The fact that South Asians' increased insulin resistance and glycaemia is strongly associated with their lower fitness levels, and that increasing physical activity is the only way to increase cardiorespiratory fitness, suggests that South Asians may need to engage in greater levels of physical activity than Europeans to achieve the same levels of cardiorespiratory fitness and minimise their metabolic risk. This has potential implications for physical activity guidance, which, at present, does not take ethnicity into account. Recent consensus statements have recommended that the BMI threshold for obesity in South Asian populations should be lowered from $30 \mathrm{~kg} / \mathrm{m}^{2}$ to BMI $25 \mathrm{~kg} / \mathrm{m}^{2}[40,41]$, in recognition of the substantially lower BMIs that are needed in South Asians to confer equivalent cardiometabolic-risk-factor profiles to those observed in populations of white European origin [4, 42]. The present data suggest that differential physical activity guidance for South Asians may also be needed. Larger epidemiological studies, and intervention trials, comparing the doseresponse relationship between (objectively measured) physical activity and risk of cardiometabolic disease in South Asians and Europeans are urgently needed to enable appropriate levels of physical activity to minimise risk in South Asian populations to be robustly quantified.

This study has a number of strengths. We were initially rigorous to exclude those with known diabetes and those with potential undiagnosed diabetes (remarkably, 13\% of South Asian men [vs 1\% of European men]) from further analysis, to prevent potential confounding. This is the largest study to compare objectively measured physical activity and cardiorespiratory fitness between South Asian and European men. Thus, differences in fitness and activity between these groups and the contribution of these factors to insulin resistance and glycaemia can be robustly assessed from the present data. Furthermore, we measured a wide range of adiposity variables and used factor analysis to derive robust summary measures of body size and composition to enable us to determine which specific features of South Asians' greater adiposity contributed to their increased insulin resistance and glycaemia. The groups were well-matched for age, BMI and SES. While South Asians spent more years in education, smoked less and drank less alcohol than the Europeans, adjusting for these factors did not change the key study outcomes: difference in $\dot{V} \mathrm{O}_{2 \max }$ remained the most important factor associated with South Asians' greater insulin resistance after adjustment for these potential confounders. However, the study does have limitations. By the nature of the recruitment methods, the study cohort represents a selfselected group, and thus a degree of caution is warranted in extrapolating the findings to the general UK South Asian population. However, as the findings with respect to fitness, physical activity, adiposity and metabolic variables in South Asians are fully consistent with the body of previously published data on this topic, this seems unlikely to have introduced substantial bias into the findings. We assessed insulin resistance using $\mathrm{HOMA}_{\mathrm{IR}}$, as the size of this single- 
centre study made use of the gold-standard euglycaemichyperinsulinaemic clamp unfeasible. Similarly, we assessed glycaemia from fasting glucose concentrations; we chose not to use $\mathrm{HbA}_{1 \mathrm{c}}$ as a marker of long-term glycaemia in our analyses because of potential confounding from known ethnic differences in glycation rates independent of glycaemia [43]. Finally, the cross-sectional nature of the study, with simultaneous assessment of exposure and outcome variables, means that it is not possible to definitively exclude reverse causality as a potential influence on the findings.

In conclusion, the present findings show that low cardiorespiratory fitness is a key factor associated with the increased insulin resistance and fasting glycaemia in middleaged South Asian, compared with European, men living in the UK. Although they were less physically active than their European counterparts, South Asians' lower fitness levels could not be explained by their lower physical activity levels, suggesting that low fitness is an innate feature of the South Asian phenotype. Though the observational nature of this study means that conclusions cannot be drawn about causality, the present data suggest that South Asians may need to engage in higher levels of physical activity than Europeans to overcome their lower innate fitness and the associated metabolic consequences. This raises the possibility that ethnicity-specific recommendations for physical activity, and thus prevention of diabetes, may be needed.

Funding NG was supported by a Fellowship from Chest, Heart and Stroke Scotland.

Duality of interest The authors declare that there is no duality of interest associated with this manuscript.

Author contributions NG, NS and JMRG conceived and designed the study. NG and JW collected experimental data. NG, DP, AM, NS and JMRG analysed and interpreted data. NG, DP and JMRG drafted the manuscript. All authors critically revised the manuscript and approved the final version.

Open Access This article is distributed under the terms of the Creative Commons Attribution Noncommercial License which permits any noncommercial use, distribution, and reproduction in any medium, provided the original author(s) and the source are credited.

\section{References}

1. Mukhopadhyay B, Forouhi NG, Fisher BM, Kesson CM, Sattar N (2006) A comparison of glycaemic and metabolic control over time among South Asian and European patients with type 2 diabetes: results from follow-up in a routine diabetes clinic. Diabet Med 23:94-98
2. Sproston K, Mindell J (eds) (2006) Health survey for England 2004. Volume 1 . The health of minority ethnic groups. The Information Centre, Leeds, UK

3. Forouhi NG, Sattar N, Tillin T, McKeigue PM, Chaturvedi N (2006) Do known risk factors explain the higher coronary heart disease mortality in South Asian compared with European men? Prospective follow-up of the Southall and Brent studies, UK. Diabetologia 49:2580-2588

4. Gray LJ, Yates T, Davies MJ et al (2011) Defining obesity cut-off points for migrant South Asians. PLoS One 6:e26464

5. Chandalia M, Lin P, Seenivasan Tet al (2007) Insulin resistance and body fat distribution in South Asian men compared to Caucasian men. PLoS One 2:e812

6. Hall LM, Moran CN, Milne GR et al (2010) Fat oxidation, fitness and skeletal muscle expression of oxidative/lipid metabolism genes in South Asians: implications for insulin resistance? PLoS One 5:e14197

7. The Interact Consortium (2012) Long-term risk of incident type 2 diabetes and measures of overall and regional obesity: the EPICInterAct Case-Cohort Study. PLoS Med 9:e1001230

8. Rheaume C, Arsenault BJ, Dumas MP et al (2011) Contributions of cardiorespiratory fitness and visceral adiposity to six-year changes in cardiometabolic risk markers in apparently healthy men and women. J Clin Endocrinol Metab 96:1462-1468

9. Forouhi NG, Jenkinson G, Thomas EL et al (1999) Relation of triglyceride stores in skeletal muscle cells to central obesity and insulin sensitivity in European and South Asian men. Diabetologia 42:932-935

10. Wei M, Gibbons LW, Mitchell TL, Kampert JB, Lee CD, Blair SN (1999) The association between cardiorespiratory fitness and impaired fasting glucose and type 2 diabetes mellitus in men. Ann Intern Med 130:89-96

11. Gill JM, Cooper AR (2008) Physical activity and prevention of type 2 diabetes mellitus. Sports Med 38:807-824

12. Gill JM, Malkova D (2006) Physical activity, fitness and cardiovascular disease risk in adults: interactions with insulin resistance and obesity. Clin Sci (Lond) 110:409-425

13. McKeigue PM, Shah B, Marmot MG (1991) Relation of central obesity and insulin resistance with high diabetes prevalence and cardiovascular risk in South Asians. Lancet 337:382-386

14. Misra A, Vikram NK (2004) Insulin resistance syndrome (metabolic syndrome) and obesity in Asian Indians: evidence and implications. Nutrition 20:482-491

15. Davey GJG, Roberts JD, Patel S et al (2000) Effects of exercise on insulin resistance in South Asians and Europeans. J Exerc Physiol 3:6-11

16. Hardy CP, Eston RG (1985) Aerobic fitness of Anglo-Saxon and Indian students. Br J Sports Med 19:217-218

17. Fischbacher CM, Hunt S, Alexander L (2004) How physically active are South Asians in the United Kingdom? A literature review. J Public Health (Oxf) 26:250-258

18. Williams ED, Stamatakis E, Chandola T, Hamer M (2011) Physical activity behaviour and coronary heart disease mortality among South Asian people in the UK: an observational longitudinal study. Heart 97:655-659

19. Yates T, Davies MJ, Gray LJ et al (2010) Levels of physical activity and relationship with markers of diabetes and cardiovascular disease risk in 5474 white European and South Asian adults screened for type 2 diabetes. Prev Med 51:290-294

20. Williams ED, Stamatakis E, Chandola T, Hamer M (2011) Assessment of physical activity levels in South Asians in the UK: findings from the Health Survey for England. J Epidemiol Community Health 65:517-521

21. Shephard RJ (2003) Limits to the measurement of habitual physical activity by questionnaires. Br J Sports Med 37:197-206

22. van Poppel MN, Chinapaw MJ, Mokkink LB, van Mechelen W, Terwee CB (2010) Physical activity questionnaires for adults: a systematic review of measurement properties. Sports Med 40:565-600 
23. Celis-Morales CA, Perez-Bravo F, Ibanez L, Salas C, Bailey ME, Gill JM (2012) Objective vs. self-reported physical activity and sedentary time: effects of measurement method on relationships with risk biomarkers. PLoS One 7:e36345

24. Atienza AA, Moser RP, Perna F et al (2011) Self-reported and objectively measured activity related to biomarkers using NHANES. Med Sci Sports Exerc 43:815-821

25. Fehily AM, Yarnell JW, Butland BK (1987) Diet and ischaemic heart disease in the Caerphilly Study. Hum Nutr Appl Nutr 41:319 326

26. Marfell-Jones M, Olds T, Stewart A, Carter L (2006) International standards for anthropometric assessment. ISAK, Potchefstroom, pp $1-133$

27. Dewit O, Fuller NJ, Fewtrell MS, Elia M, Wells JC (2000) Whole body air displacement plethysmography compared with hydrodensitometry for body composition analysis. Arch Dis Child 82:159-164

28. Matthews DR, Hosker JP, Rudenski AS, Naylor BA, Treacher DF, Turner RC (1985) Homeostasis model assessment: insulin resistance and beta-cell function from fasting plasma glucose and insulin concentrations in man. Diabetologia 28:412-419

29. El Assaad MA, Topouchian JA, Asmar RG (2003) Evaluation of two devices for self-measurement of blood pressure according to the international protocol: the Omron M5-I and the Omron 705IT. Blood Press Monit 8:127-133

30. Taylor HL, Burskirk E, Henschel A (1955) Maximal oxygen uptake as an objective measure of cardio-respiratory fitness. J Appl Physiol 8:73-80

31. Howley ET, Bassett DR Jr, Welch HG (1995) Criteria for maximal oxygen uptake: review and commentary. Med Sci Sports Exerc 27:1292-1301

32. Freedson PS, Melanson E, Sirard J (1998) Calibration of the Computer Science and Applications, Inc. accelerometer. Med Sci Sports Exerc 30:777-781
33. Troiano RP, Berrigan D, Dodd KW, Masse LC, Tilert $\mathrm{T}$, McDowell M (2008) Physical activity in the United States measured by accelerometer. Med Sci Sports Exerc 40:181-188

34. Hagstromer M, Oja P, Sjostrom M (2007) Physical activity and inactivity in an adult population assessed by accelerometry. Med Sci Sports Exerc 39:1502-1508

35. Schmitt TA (2011) Current methodological considerations in exploratory and confirmatory factor analysis. J Psychoeduc Assess 29:304-321

36. Wisloff U, Najjar SM, Ellingsen O et al (2005) Cardiovascular risk factors emerge after artificial selection for low aerobic capacity. Science 307:418-420

37. Ceaser TG, Fitzhugh EC, Thompson DL, Bassett DR Jr (2013) Association of physical activity, fitness, and race: NHANES 19992004. Med Sci Sports Exerc 45:286-293

38. Bouchard C, Daw EW, Rice T et al (1998) Familial resemblance for $\mathrm{VO}_{2 \max }$ in the sedentary state: the HERITAGE family study. Med Sci Sports Exerc 30:252-258

39. Bouchard C, Lesage R, Lortie G et al (1986) Aerobic performance in brothers, dizygotic and monozygotic twins. Med Sci Sports Exerc 18:639-646

40. Misra A, Chowbey P, Makkar BM et al (2009) Consensus statement for diagnosis of obesity, abdominal obesity and the metabolic syndrome for Asian Indians and recommendations for physical activity, medical and surgical management. J Assoc Physicians India 57:163-170

41. Kumar S, Hanif W, Zaman MJ, Sattar N, Patel K, Khunti K (2011) Lower thresholds for diagnosis and management of obesity in British South Asians. Int J Clin Pract 65:375-385

42. Razak F, Anand SS, Shannon H et al (2007) Defining obesity cut points in a multiethnic population. Circulation 115:2111-2118

43. Herman WH, Cohen RM (2012) Racial and ethnic differences in the relationship between $\mathrm{HbA}_{1 \mathrm{c}}$ and blood glucose: implications for the diagnosis of diabetes. J Clin Endocrinol Metab 97:1067-1072 